\title{
Estimation of silver content in some photographic wastes
}

\author{
Orubite - Okorosaye, $\mathrm{K}$ and Jack, I.R
}

\author{
Department of chemistry, Rivers state university of Science and Technology, Nkpolu - \\ Oroworukwo' Port Harcourt, Rivers state. Nigeria.
}

\begin{abstract}
The concentration of silver in some photographic wastes (photographic solution, stabilizer solution and photographic films) has been determined in this study. Plantain ash solution (PAS) of different concentrations was used as solution for stripping the films and as extractant for the photographic solutions. Products obtained were analysed for silver content. The concentration of silver was measured using UV-visible spectrophotometer at a wavelength of $380 \mathrm{~nm}$, path length $1 \mathrm{~cm}$ using silver nitrate for calibration. Results obtained revealed that plantain ash solution extracted silver from the various wastes in all the concentrations of PAS used. However the silver content was observed to be highest in the photographic film and fixer solution and lowest for stabilizer solution in the particular instance. In all the photographic wastes studied, it was observed that although more products were recovered by using higher concentrations of PAS, higher concentrations of silver ions were obtained when lower concentrations of PAS were used $(0.1500-0.8450 \mathrm{M})$. Therefore lower concentrations of PAS can be used for leaching of photographic wastes of silver.
\end{abstract}

Keywords: $\quad$ Silver, photographic wastes, unripe plantain peels ash solution (PAS).

\section{INTRODUCTION}

Silver which belongs to the group $1 \mathrm{~B}$ elements has a larger ionization energy than the group $1 \mathrm{~A}$ elements (alkali metals) thereby making the group 1B elements much less reactive. It has been reported that $25 \%$ of the world's silver needs are supplied by recycling and that $75 \%$ of this is obtained from photographic waste (Dahne et al 1990). The sensitivity of silver to light has resulted in its wide application in most photographic and x-ray materials (Mendoza et al 1996). The fixer solution is a photographic waste solution of sodium or ammonium thiosulphate, that converts the silver halide into water soluble silver thiosulphate complexes which diffuse from the emulsion into the fixing bath (Grant 1979). Another photographic waste solution that contains silver is the spent stabilizer solution. In wastewaters the free silver ion is very toxic to aquatic organism even at trace concentrations. Thus the removal of silver from these wastes is of both economic and environmental benefit. While the recovered silver may be subsequently recycled to the process, the silver contents need to be reduced to meet the recommended allowable silver discharge limit of 0.1 $1.0 \mathrm{mg} / \mathrm{L}$ (Mendoza et al 1996). Plantain, ( Musa Paradisiaca) is a green to yellow boat shaped fruit of a large shrub, widely grown in the tropics. It is eaten all over Africa and in Southern and Central America, with the peels being discarded as wastes. Plantain peels have been used for the production of certain chemicals such as ethanol and in medicine for the prevention of hypokalaemia etc. Recently plantain peels ash solution has been used as stripping solution to recover silver from $x$-ray films (Orubite and Jack 2011).

\section{RESEARCH METHODOLOGY}

Photographic films, fixer solution and stabilizer solution were collected from (Photo finesse) a photographic studio along Aggrey Road in Port Harcourt Rivers State while the x-ray films were obtained from the Braithwaite Memorial Hospital in Port Harcourt.

Peels of the unripe plantains were weighed and sun dried for 3 days (72 hours) at ambient temperature. After sun drying, the peels were finally dried in the oven at a temperature of $80^{\circ} \mathrm{C}$ for six hours. Weights of ash ranging from $10-200 \mathrm{~g}$ were dissolved separately in $500 \mathrm{ml}$ of distilled water and allowed to stand for 72 hours with occasional shaking. Thereafter they were filtered and the solutions obtained were standardized using $1 \mathrm{M} \mathrm{HCl}$ after recording the $\mathrm{pH}$ values.

Recovery of Silver from Liquid Photographic Wastes: The extraction process was carried out by mixing an equal volume $(25 \mathrm{ml})$ of liquid photographic waste and unripe plantain peel ash solution using a mechanical shaker at a speed of 800rpm for 6 hours, after which the two phases separated. The supernatant phase was carefully decanted off into a 
clean specimen bottle. The sediment containing colloidal black gelatin layer was dried in an oven at a temperature of $80^{\circ} \mathrm{C}$ and later stored in a desiccator and kept away from light. This process was repeated for all concentrations of plantain ash solution. All experiments were carried out at ambient temperature $\left(26^{\circ} \mathrm{C}\right)$.

Recovery of Silver from Photographic and X-ray Films: The used films of size $17.8 \times 23.7 \mathrm{~cm}^{2}$ (i.e. Xray films and photographic films) were washed with distilled water and wiped with cotton impregnated with ethanol and was cut into $2 \times 2 \mathrm{~cm}^{2}$ after being dried in an oven at $60^{\circ} \mathrm{C}$ for 30 minutes. The films were weighed and stirred in series in a beaker containing $150 \mathrm{ml}$ of various concentrations of unripe plantain peel ash solution for the $10 \mathrm{~g}-200 \mathrm{~g}$ ash at $100^{\circ} \mathrm{C}$ in a water bath until the gelatin silver layer is stripped off completely (Nuri et al 2003 ). The stripped films were carefully transferred into a clean beaker, dried and weighed. The resulting solution was stirred vigorously in a water bath at $100^{\circ} \mathrm{C}$ until coarse - grained substance was observed. The solution was carefully transferred into an evaporating dish and heated to dryness. The dish and its content was weighed and stored in a desiccator and kept away from light. The time taken for complete stripping at different concentrations of plantain ash solutions was recorded. Complete stripping of the film was indicated by the appearance of a clear white colouration ( for photographic film) or a light blue colouration ( for $x$-ray) film. This process was repeated for all concentrations of the plantain peel ash solution.

Test for Silver: The recovered product was tested for silver ion using the streak test with nitric acid and potassium chloride.

UV-visible Analysis: $1.0 \mathrm{~g}$ each of the recovered product from the various photographic wastes was weighed and dissolved in $5 \mathrm{ml}$ deionized water and $10 \mathrm{ml}$ concentrated $\mathrm{HNO}_{3}$ and made up to $100 \mathrm{ml}$ with deionized water. $0.4 \mathrm{M}-4.0 \mathrm{M}$ solutions of analar grade $\mathrm{AgNO}_{3}$ was prepared for the absorbance measurement at a wavelength of $380 \mathrm{~nm}$ and path length of $1 \mathrm{~cm}$.

\section{RESULTS AND DISCUSSION}

Table 1 confirms the alkaline solution of PAS. pH values range from 10.2 to 11.2 . Plantain peels ash like most land plants contain potassium carbonate. Therefore the ash in solution produces potassium hydroxide $(\mathrm{KOH})$ according to the equation;

$$
\mathrm{K}_{2} \mathrm{CO}_{3(\mathrm{~s})}+2 \mathrm{H}_{2} \mathrm{O}_{(\mathrm{aq})} \longrightarrow 2 \mathrm{KOH}_{(\mathrm{l})}+\mathrm{H}_{2} \mathrm{CO}_{3(\mathrm{aq})}
$$

The resulting solution will be more alkaline since $\mathrm{H}_{2} \mathrm{CO}_{3}$ is a weak acid and only feebly ionized. As expected the concentration of PAS increased with increase in quantity of ash dissolved.

Silver recovery: As reported in our previous paper (Orubite and Jack 2011) complete stripping was achieved at temperature range $80-100^{\circ} \mathrm{C}$ for x-ray and photographic film. It was observed that the higher the quantity of PAS the shorter the stripping time. This may be attributed to the fact that more hydroxyl ions are available for reaction with the silver ions.

Test for silver ion: The appearance of a milky precipitate was observed as a proof for the presence of silver in all the products obtained.

Measurement of silver ion: The calibration curve for $\mathrm{AgNO}_{3}$ is shown in Graph 1

The absorbance measurement for silver ion in each recovered product is recorded in Table 3.

From the calibration curve obtained for silver nitrate the concentrations of silver ion in the products were determined by extrapolations (Table 4).

As shown in Table4 highest amount of silver ion recovered was in the photographic film

(7.72M ) when PAS concentration of $0.2930 \mathrm{M}$ was used. X- ray films also recorded the highest amount of silver ions $(3.12 \mathrm{M})$ at this same PAS concentration. For the solutions ( stabilizer and fixer ), highest amounts of silver ion were recorded for PAS concentration between 0.5690 - 0.8450M ( Fixer solution $6.38 \mathrm{M}$ and stabilizer solution $0.372 \mathrm{M}$ ). From the PAS concentrations mentioned so far it is evident that more silver ions were obtained in the films than the solutions. This could be attributed to the different sources they were collected. The solutions were used to wash photographic films before collection while the films were stripped of the silver in the laboratory. There is no knowledge of number of films that had been washed in them before collection. It is therefore difficult to conclude that the films contain more silver ions that the photographic solutions. For the purposes of the research since equal volumes of solutions were used the comparison can be based on that. Again the methods of recovery may have contributed to the significant difference in the amount of silver ion in the two sources. The films were stripped with PAS to obtain the product while for the solutions direct precipitation 
was done with the PAS solution. In all it is noteworthy that PAS extracted silver ions from the various wastes. Generally in all the wastes, table 4 also reveals that lower concentrations of silver ions were obtained in higher concentrations of PAS. Thus for PAS concentration of $2.0792 \mathrm{M}$ and $2.7670 \mathrm{M}$ all the various wastes recorded low concentration of silver ions extracted. This trend may be attributed to the complex formation property of the silver ion. Essentially all of the silver may have been present as the $\mathrm{Ag}^{+}$ion at very low concentrations of PAS. As the PAS concentration increased, the dominant species soon became the two-coordinate $\mathrm{Ag}(\mathrm{OH})_{2}{ }^{+}$ion which is not available as silver ion, hence the low concentration of silver ion recorded. From the above it follows that the observation that higher conc. of PAS correspond to faster stripping time is not a means to obtaining more silver ions. At these high PAS concentrations complex ions are rather in existence in the solutions.

\section{CONCLUSION}

Plantain ash solution (PAS) successfully leached silver ions from photographic wastes. This work further reveals that the efficiency of PAS is more at lower concentrations $(0.1500-0.8450 \mathrm{M})$ that at higher concentrations $(2.0792-2.7670 \mathrm{M})$. At higher concentrations of PAS, silver ions form a complex with the hydroxyl ion in PAS and are not available for measurement. However the fact remains that the silver ions have been leached from the wastes. The free silver ions is toxic to the environment even in trace quantities and so any means of reducing the silver content will be an advantage to the environment. Moreover recovered silver can be recycled into the system. Plantain peel, waste discarded after taking the edible pulp is hereby established as a useful substance in silver recovery.

Table 1: Concentration of unripe plantain ash solution (PAS)

\begin{tabular}{|l|l|l|l|l|l|l|l|}
\hline $\begin{array}{l}\text { Conc of } \\
\text { acid (M) }\end{array}$ & $\begin{array}{l}\text { Amt of } \\
\text { PAS (g) in } \\
500 \mathrm{ml} \mathrm{sol}\end{array}$ & $\begin{array}{l}\mathrm{pH} \text { of } \\
\text { unripe PAS } \\
\text { sol }\end{array}$ & $\begin{array}{l}1 \mathrm{st} \text { Titre } \\
\left(\mathrm{cm}^{3}\right)\end{array}$ & $\begin{array}{l}2^{\text {nd }} \text { Titre } \\
\left(\mathrm{cm}^{3}\right)\end{array}$ & $\begin{array}{l}3^{\text {rd }} \text { Titre } \\
\left(\mathrm{cm}^{3}\right)\end{array}$ & $\begin{array}{l}\text { Vol of acid } \\
\text { used }\end{array}$ & $\begin{array}{l}\text { Conc } \\
\text { PAS }\end{array}$ \\
\hline 1.0 & 10.00 & 10.7 & 3.70 & 3.80 & 3.75 & 3.75 & $\begin{array}{l}\text { Acid used } \\
\mathrm{HCl} \\
\text { indicator } \\
\text { methyl } \\
\text { orange }\end{array}$ \\
\hline 1.0 & 20.00 & 11.0 & 7.30 & 7.30 & 7.40 & 7.33 & 0.2930 \\
\hline 1.0 & 30.00 & 11.1 & 10.70 & 10.80 & 10.80 & 10.77 & 0.4310 \\
\hline 1.0 & 40.00 & 11.2 & 14.25 & 14.20 & 14.25 & 14.23 & 0.5690 \\
\hline 1.0 & 50.00 & 11.2 & 17.80 & 17.90 & 17.90 & 17.87 & 0.7150 \\
\hline 1.0 & 60.00 & 11.0 & 21.15 & 21.10 & 21.10 & 21.15 & 0.8450 \\
\hline 1.0 & 100.00 & 10.4 & 34.77 & 34.87 & 34.82 & 34.82 & 1.3930 \\
\hline 1.0 & 150.00 & 10.2 & 51.93 & 52.03 & 51.98 & 51.98 & 2.0792 \\
\hline 1.0 & 200.00 & 10.4 & 69.10 & 69.20 & 69.25 & 69.18 & 2.7670 \\
\hline
\end{tabular}

Table 2

\begin{tabular}{|l|c|c|c|}
\hline \multicolumn{2}{|c|}{ PHOTOGRAPHIC FILM } & \multicolumn{2}{c|}{ X-RAY FILM } \\
\hline PAS conc.(M) & TIME (Min) & PAS conc.(M) & TIME (Min) \\
\hline 0.1500 & 142 & 0.1500 & 186 \\
\hline 0.2930 & 122 & 0.2930 & 160 \\
\hline 0.4310 & 98 & 0.4310 & 120 \\
\hline 0.5690 & 68 & 0.5690 & 104 \\
\hline 0.7150 & 52 & 0.7150 & 98 \\
\hline 0.8450 & 44 & 0.8450 & 64 \\
\hline 1.3930 & 38 & 1.3930 & 55 \\
\hline 2.0792 & 30 & 2.0792 & 48 \\
\hline 2.7670 & 25 & 2.7670 & \\
\hline
\end{tabular}


Am. J. Sci. Ind. Res., 2012, 3(6): 390-394

Graph 1 Calibration curve for $\mathrm{AgNO}_{3}$

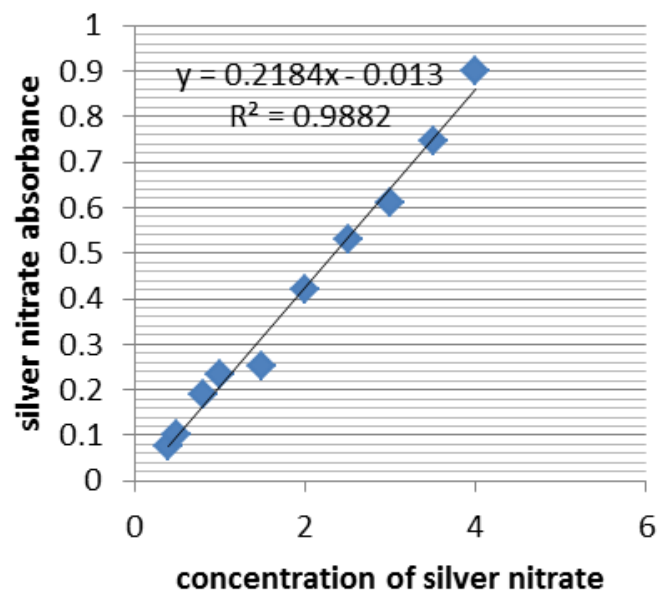

Table 3 Absorbances of recovered products from UV analysis

\begin{tabular}{|c|c|c|c|c|}
\hline & \multicolumn{4}{|c|}{ Absorbances of recovered products from UV analysis (Wavelength $380 \mathrm{~nm}$ and $1 \mathrm{~cm}$ pathlength ) } \\
\hline Conc of PAS & Fixer solution & Stabilizer solution & Photographic film & X- ray film \\
\hline 0.1500 & 0.6611. & 1.500 & 1.434 & 0.591 \\
\hline 0.2930 & 0.837 & 0.990 & 1.636 & 0.664 \\
\hline 0.4310 & 0.447 & 1.190 & 1.568 & 0.177 \\
\hline 0.5690 & 0.543 & 1.75 & 1.372 & 0.301 \\
\hline 0.7150 & 0.959 & 1.192 & 1.479 & 0.170 \\
\hline 0.8450 & 1.346 & 1.250 & 0.926 & 0.226 \\
\hline 1.3930 & 0.446 & 1.550 & 0.626 & 0.128 \\
\hline 2.0792 & 0.155 & 0.650 & 0.683 & 0.124 \\
\hline 2.7670 & 0.246 & 0.100 & 0.363 & 0.120 \\
\hline
\end{tabular}


Am. J. Sci. Ind. Res., 2012, 3(6): 390-394

Table 4 Concentrations of silver ion in the products

\begin{tabular}{|l|l|l|l|l|}
\hline $\begin{array}{l}\text { Conc.of } \\
\text { PAS }\end{array}$ & $\begin{array}{l}\text { Fixer } \\
\text { solution }\end{array}$ & $\begin{array}{l}\text { Stabilizer } \\
\text { solution }\end{array}$ & $\begin{array}{l}\text { Photographic } \\
\text { film }\end{array}$ & $\begin{array}{l}\text { X- ray } \\
\text { film }\end{array}$ \\
\hline 0.1500 & 3.100 & 0.309 & 6.750 & 2.770 \\
\hline 0.2930 & 3.990 & 0.198 & 7.720 & 3.120 \\
\hline 0.4310 & 2.150 & 0.238 & 7.420 & 0.855 \\
\hline 0.5690 & 2.570 & 0.372 & 6.48 & 1.45 \\
\hline 0.7150 & 4.55 & 0.239 & 7.000 & 0.850 \\
\hline 0.8450 & 6.380 & 0.262 & 4.380 & 1.080 \\
\hline 1.3930 & 2.149 & 0.315 & 2.950 & 0.62 \\
\hline 2.0792 & 0.780 & 0.129 & 3.220 & 0.58 \\
\hline 2.7670 & 1.180 & 0.025 & 1.72 & 0.56 \\
\hline
\end{tabular}

\section{ACKNOWLEDGEMENT;}

The authors wish to acknowledge the contributions of our students, Mr Harold Anabraba , T, Jaja and Wisdom Tyger to this work.

\section{REFERENCES}

Dahne, W. and Schriftenr. (1990) GDMB. 63231 - 247

Gill, L. S. (1992): Ethnomedicinal uses of plants in Nigeria. University of Benin Press, Benin City, Nigeria, Pp. 169-170.

Godwin, O.O. (2001): Practical Chemistry for Schools and Colleges. New edition. Gbabeks publishers limited, Ibadan Pp. 130-132.

Grant, H. (1979): Modern Photographic processing, vol. 1, John Wiley and sons, New York.

Hammond, C.R. (2000): The elements in handbook of chemistry and Physics $81^{\text {st }}$ edition. CRC press. ISBN 0849304814.

Mendoza, C.S. and Kanata, S. (1996): "Silver extraction for pollution Control of photographic fixing solution with tetramethytturam disulphide" Bull. Chem. Soc. Jpn., $69,3499-3504$.

Nuri Nakiboglu; duygu Toscali and Gurel NisliL a novel recovery method from photographic films with $\mathrm{NaOH}$ stripping; Turk J chem.. 27 (2003), 127 -133.

Nichols, Kenneth D. (1987): The road to trinity. Morrow, New York:Morrow. Pg. 42. ISBN 068806910x.

Orubite-Okorosaye, K. and Jack, I. R. (2011): Recovery of silver from waste $x$-ray films using plantain peels ash solution.International journal of physical science volume 3, Number 1.

Raymond, C. (2002): Chemistry, McGraw-Hill Companies Inc. New York, $7^{\text {th }}$ Edition, Pg. 318, 791, 848. 